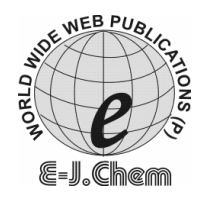

http://www.e-journals.net

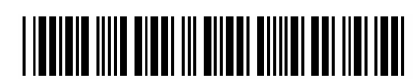

ISSN: 0973-4945; CODEN ECJHAO

E-Journal of Chemistry 2009, 6(3), 780-784

\title{
Validated Spectrophotometric Estimation of Famciclovir in Tablet Dosage Form
}

\author{
J. ADLIN JINO NESALIN, C. JOSE GNANA BABU*, \\ G. VIJAYA KUMAR and T. TAMIZH MANI \\ Research Laboratory, Bharathi College of Pharmacy, \\ Bharathi Nagara, K.M.Doddi, Maddur Taluk, Mandya District, \\ Karnataka - 571 422, India. \\ josejino2@yahoo.com
}

Received 5 December 2008; Accepted 5 February 2009

\begin{abstract}
Two simple and sensitive spectrophotometric methods have been developed for the estimation of Famciclovir (FCR) in bulk and tablet dosage form. Methods A and B are based on the formation of ion-pair complexes of the drug with dyes such as orange II (OG-II) and alizarin red S (AR-S) in acidic medium followed by their extraction with chloroform to give colored chromogen with absorption maxima at $480 \mathrm{~nm}$ and $440 \mathrm{~nm}$ respectively. Beer's law is valid in the concentration range of $2-10 \mathrm{mcg} / \mathrm{mL}$ for both the methods. These developed methods were validated for precision, accuracy, ruggedness and robustness. Statistical analysis proves that the methods are reproducible and selective for the routine analysis of the said drug.
\end{abstract}

Keywords: Famciclovir, Spectrophotometric, Beer's law, Drug

\section{Introduction}

FCR is an orally administered prodrug of the antiviral agent ${ }^{1}$ penciclovir. Chemically, FCR is known as 2-[2-(2-amino-9H-purin-9-yl) ethyl] - 1, 3-propanediol diacetate ${ }^{2}$ (Figure 1). Its molecular weight is 321.3 . It is a synthetic acyclic guanine derivative. FCR is a white to pale yellow solid. It is freely soluble in acetone and methanol and sparingly soluble in ethanol and isopropanol. FCR is marketed as a white, film-coated tablet. The $125 \mathrm{mg}$ and $250 \mathrm{mg}$ tablets are round; the $500 \mathrm{mg}$ tablets are oval. Inactive ingredients consist of hydroxypropyl cellulose, hydroxypropyl methylcellulose, lactose, magnesium stearate, polyethylene glycols, sodium starch glycolate and titanium dioxide ${ }^{3,4}$. Extensive literature survey revealed that the determination of the drug in pure and tablet dosage form is not official in any pharmacopoeia and therefore, require much more investigation. Few analytical methods have been reported for the estimation of FCR in biological fluids or pharmaceutical formulations 
include liquid chromatography $y^{5,6}$ and UV-visible spectrophotometry ${ }^{7-9}$. The objective of the work is to develop new spectrophotometric methods for its estimation in bulk and tablet dosage form with good accuracy, simplicity, precision and economy. The proposed methods are based on the ion-pair extractive spectrophotometry ${ }^{10}$.

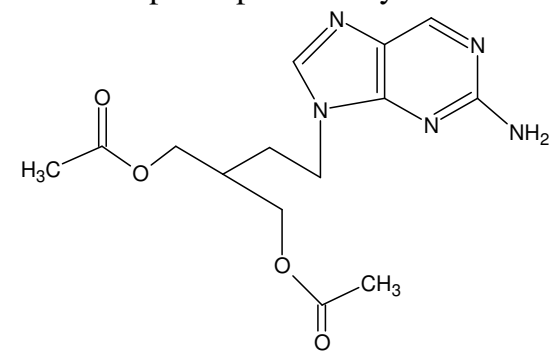

\section{Experimental}

Figure 1. Chemical structure of famciclovir.

A Schimadzu UV/VIS spectrophotometer (Model 1201, Schimadzu, Japan) was employed for all the spectral measurements. All the chemicals used in the investigation were of analytical grade. The aqueous solution of OG-II $(0.4 \% \mathrm{w} / \mathrm{v})$, AR-S $(0.5 \% \mathrm{w} / \mathrm{v})$ and $0.1 \mathrm{M}$ hydrochloric acid $(\mathrm{HCl})$ were prepared. The chemical structure of OG-II and AR-S are shown in Figure 2 and 3 respectively.<smiles>[N+]=[N+]=Nc1ccc(S(=O)(=O)[O-])cc1</smiles>

Figure 2. Chemical structure of orange II.<smiles>NS(=O)(=O)c1cc2c(c(O)c1O)C(=O)C1C=CC=CC1C2=O</smiles>

Figure 3. Chemical structure of alizarin red $\mathrm{S}$.

Standard solution of FCR was prepared by dissolving $100 \mathrm{mg}$ in $100 \mathrm{~mL}$ and diluting $10 \mathrm{~mL}$ of this solution to $100 \mathrm{~mL}$ with methanol $(100 \mathrm{mcg} / \mathrm{mL})$. The method was extended for determination of FCR in tablet dosage form. The tablet containing 250 and $500 \mathrm{mg}$ strength were taken. Twenty tablets were weighed and powdered. The tablet powder equivalent to $100 \mathrm{mg}$ of FCR was transferred into $100 \mathrm{~mL}$ volumetric flask containing $50 \mathrm{~mL}$ of methanol and flask was kept for ultrasonication for $5 \mathrm{~min}$, then it was diluted up to the mark with methanol and the solution was filtered through Whatman filter paper No. 41. From the above solution $10 \mathrm{~mL}$ was pipetted out into a $100 \mathrm{~mL}$ volumetric flask and the volume was made up to the mark with methanol. The final concentration of FCR was brought to $100 \mathrm{mcg} / \mathrm{mL}$ with methanol and 
used for the analysis. In method A, aliquots of FCR ranging from 0.2-1.0 of standard solution were transferred into a series of separating funnel. To each separating funnel $1 \mathrm{~mL}$ of $0.4 \%$ w/v OG-II solution and $2 \mathrm{~mL}$ of $0.1 \mathrm{M} \mathrm{HCl}$ solution were added and the volume of the aqueous layer was adjusted to $10 \mathrm{~mL}$ with distilled water. The aqueous layer was extracted twice with chloroform. The combined chloroform extracts were collected and diluted to $10 \mathrm{~mL}$ with chloroform. The absorbance were measured at $480 \mathrm{~nm}$ against the reagent blank prepared simultaneously. The amount of the drug in a sample was calculated from the calibration graph. In method B, aliquots of FCR ranging from 1-5 mL of standard solution were transferred into a series of separating funnel. To each separating funnel $1 \mathrm{~mL}$ of $0.5 \% \mathrm{w} / \mathrm{v}$ AR-S solution and $2 \mathrm{~mL} 0.1 \mathrm{M} \mathrm{HCl}$ solution were added and the volume of the aqueous layer was adjusted to $10 \mathrm{~mL}$ with distilled water. The aqueous layer was extracted twice with chloroform. The combined chloroform extracts were collected and diluted to $10 \mathrm{~mL}$ with chloroform. The absorbance were measured at $440 \mathrm{~nm}$ against the reagent blank prepared simultaneously. The amount of the drug in a sample was calculated from the calibration graph.

\section{Results and Discussion}

The absorption spectral analysis shows the $\lambda$ max of FCR was found to be $480 \mathrm{~nm}$ for method A and $440 \mathrm{~nm}$ for method $\mathrm{B}$. The calibration curve was obtained for a series of concentration in the range of $2-10 \mathrm{mcg} / \mathrm{mL}$ for both the methods (Figure $4 \& 5$ ).

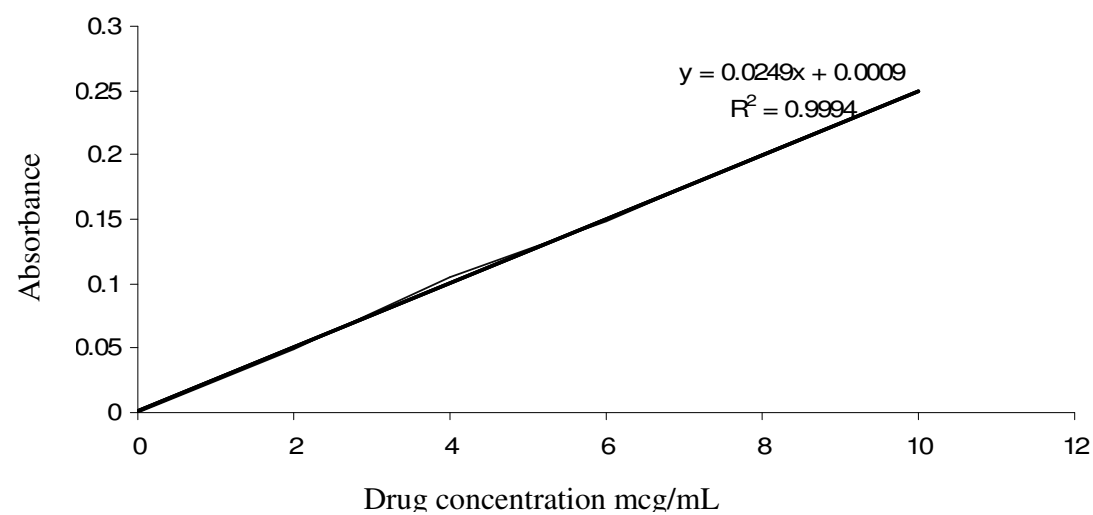

Figure 4. Calibration curve of FCR by method A.

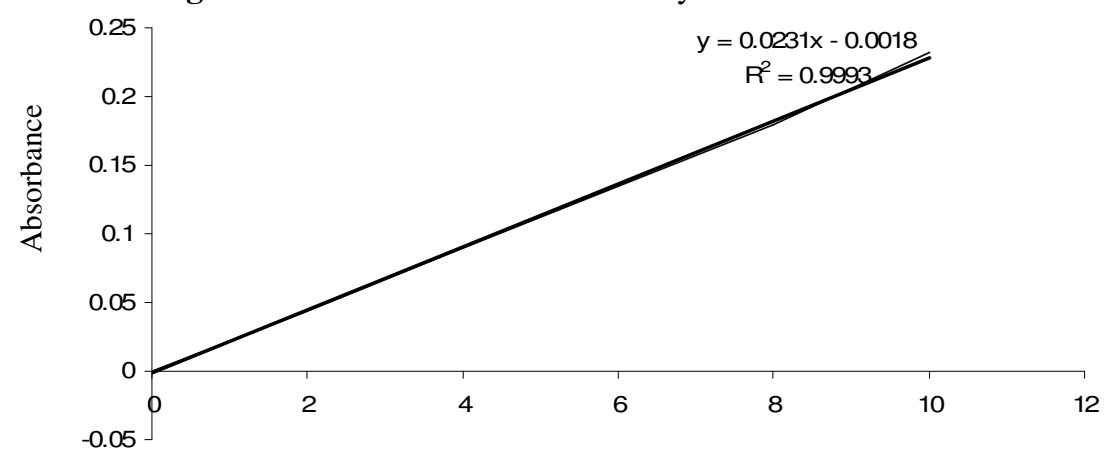

Drug concentration $\mathrm{mcg} / \mathrm{mL}$

Figure 5. Calibration curve of FCR by method B. 
They were found to be linear and hence, suitable for the estimation of the drug. The slope, intercept, correlation coefficient and optical characteristics are summarized in Table 1. Regression analysis of Beer's law plot revealed a good correlation. The effects of various excipients generally present in the tablet dosage form of famciclovir were investigated. The results indicated that they did not interfere in the assay in amounts far in excess of their normal occurrence in it. The proposed methods were validated as per the ICH guidelines ${ }^{11-13}$. The precision was measured in terms of repeatability, which was determined by sufficient number of aliquots of a homogenous sample. The \%RSD was found and lying with in \pm 2.0 . This showed that the precision of the methods are satisfactory. The recovery technique was performed to study the accuracy and reproducibility of the proposed methods. For this, known quantities of the FCR solution were mixed with definite amounts of pre-analyzed formulations and the mixtures were analyzed. The total amount of FCR was determined by using the proposed methods and the amount of added drug was calculated by the difference. The \%RSD was less than \pm 2.0 . This showed that the recoveries of famciclovir by the proposed methods are satisfactory and the results are shown in Table 2. Ruggedness and Robustness were determined and the \%RSD values were calculated from precision study was less than \pm 2.0 . limit of detection (LOD) and limit of quantitation (LOQ) were determined by the proposed methods.

Table 1. Optical characteristics of the proposed methods.

\begin{tabular}{lcc}
\hline \multicolumn{1}{c}{ Parameters } & Method A & Method B \\
\hline Absorbance maximum, $\mathrm{nm}$ & 480 & 440 \\
Linearity range, mcg/mL & $2-10$ & $2-10$ \\
Correlation coefficient $\left(\mathrm{r}^{2}\right)$ & 0.9884 & 0.9987 \\
Regression equation & $\mathrm{Y}=0.0249 \mathrm{X}+0.0009$ & $\mathrm{Y}=0.0231 \mathrm{X}-0.0012$ \\
Slope & 0.0249 & 0.0231 \\
Intercept & 0.0009 & 0.0011 \\
Limit of detection, $\mathrm{mcg} / \mathrm{mL}$ & 0.63 & 0.66 \\
Limit of quantitation, $\mathrm{mcg} / \mathrm{mL}$ & 1.89 & 1.98 \\
\hline
\end{tabular}

Table 2. Summary of validation parameters.

\begin{tabular}{lcccc}
\hline \multicolumn{1}{c}{ Parameters } & \multicolumn{2}{c}{ Method A } & \multicolumn{2}{c}{ Method B } \\
\hline Label claim, Tablet-mg & 250 & 500 & 500 & 500 \\
Amount found \pm SEM $^{\mathrm{a}}$ & $250.2 \pm 0.226$ & $500.3 \pm 0.220$ & $250.4 \pm 0.222$ & $500.4 \pm 0.221$ \\
Precision, RSD, \% $^{\mathrm{a}}$ & 0.986 & 0.823 & 0.786 & 0.974 \\
$\%$ Recovery \pm SEM & $100.3 \pm 0.74$ & $100.8 \pm 0.53$ & $100.8 \pm 0.54$ & $99.8 \pm 0.64$ \\
Recovery, RSD, \% & 0.78 & 0.98 & 0.92 & 0.71 \\
\hline
\end{tabular}

${ }^{a}$ Mean of six determinations, SEM indicates standard error mean, RSD indicates relative standard deviation

\section{Conclusion}

Thus it can be concluded that the methods developed in the present investigation are simple, sensitive, accurate, rapid and precise. Hence, the above said methods can be successfully applied for the estimation of FCR in tablet dosage form.

\section{Acknowledgement}

The authors are thankful to the management of Bharathi College of Pharmacy, Mandya for their kind cooperation in the completion of this work. 


\section{References}

1. Indian Drug Review, 2004, 10(3), 493-494.

2. Budavari S, Eds. In The Merck index; $13^{\text {th }}$ Edition; An encyclopedia of chemicals, Drugs and Biologicals; Division of Merck and co, Inc Rahway New Jersey, U.S.A., 2001, 3960.

3. Sweetman S C, Martindale The complete Drug Reference $34^{\text {th }}$ Ed., The Pharmaceutical Press: London, 2002, 620.

4. http://www.rxlist.com/famvir-drug.htm.

5. Srinivas Vishnumulaka, Narasimha rao medicherla and Allam Appa Rao, E J Chem., 2008, 5, 58-67.

6. $\quad$ Shui Wang W and Zu Qin G, Chinese J Antibiotics, 2007, 32, 159-162.

7. Vamshi Krishna M, Madhavi Latha P V and Gowri Sankar D, E J Chem., 2007, 4, 50-52.

8. Srinubabu Gadila, Sudharani Batchu and Sridar Lade, Chem Pharm Bull., 2006, 54, 819-822.

9. Nizamuddin S, Gurupadayya B M and Ravi M C, Indian J Pharm Sci., 2007, 69, 451-453.

10. Becket A H and Stenlake J B, Practical Pharmaceutical Chemistry $4^{\text {th }}$ Edition, CBS Publishers and distributors, New Delhi, Part 2, 304.

11. Robert A Nash and Alfred $\mathrm{H}$ Wachter, Pharmaceutical Process Validation. An international $3^{\text {rd }}$ Edition. New York. James Swarbrick, North Carolina, Revised and Expanded, Volume 129, Marcel Dekker, Inc., 507-522.

12. International Conference on Harmonization of Technical Requirements for the Registration of Pharmaceuticals for Human use. Validation of Analytical procedures: Methodology. ICH-Q2B, Geneva, 1996; (CPMP/ICH/281/95), Internet: http://www.nihs.go.jp/drug/validation/q2bwww.html.

13. Green J M, Anal Chem., 1996, 68, 305A-309A. 


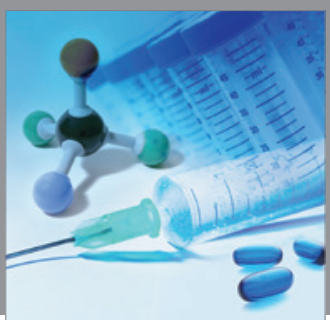

International Journal of

Medicinal Chemistry

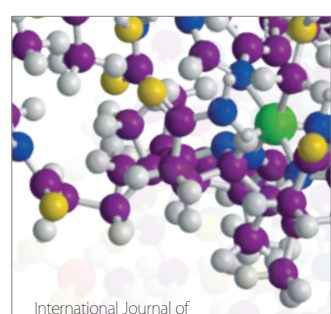

Carbohydrate Chemistry

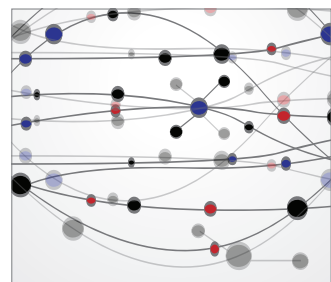

The Scientific World Journal
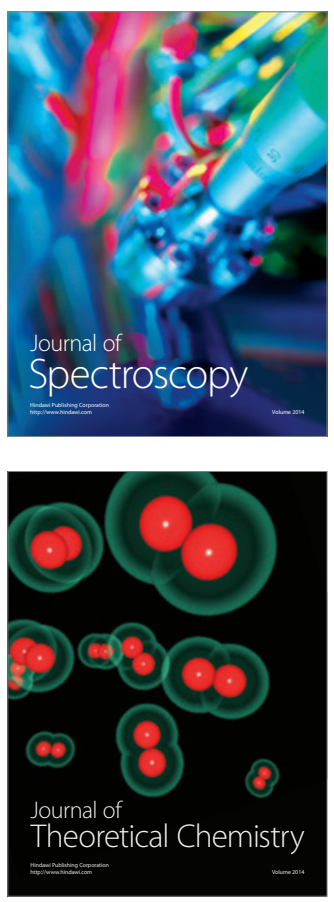
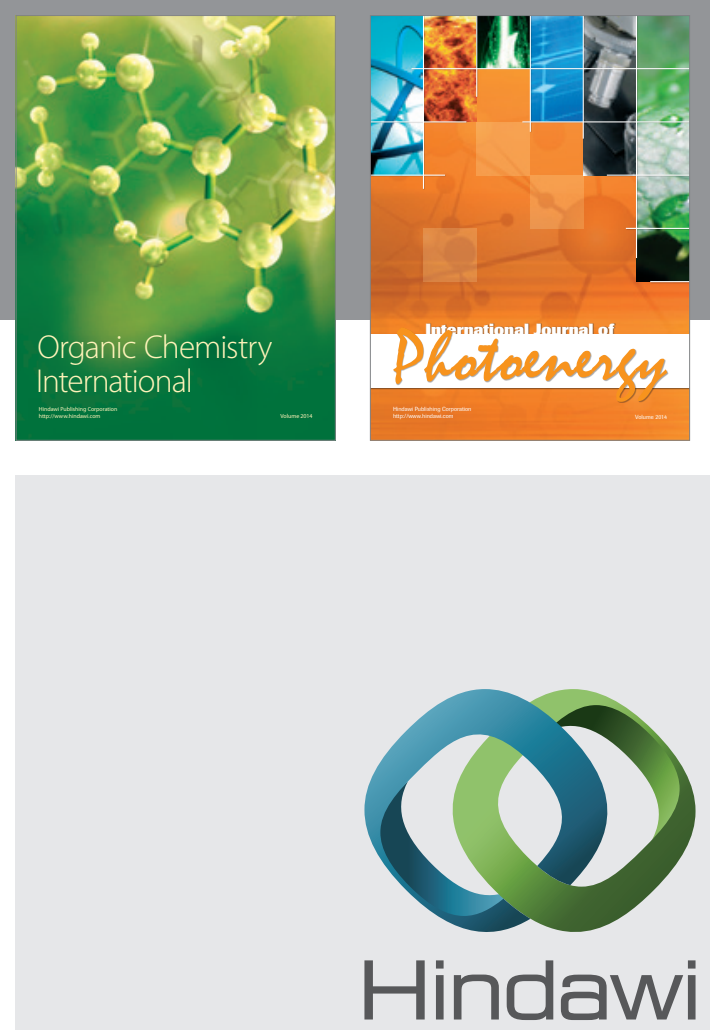

Submit your manuscripts at

http://www.hindawi.com
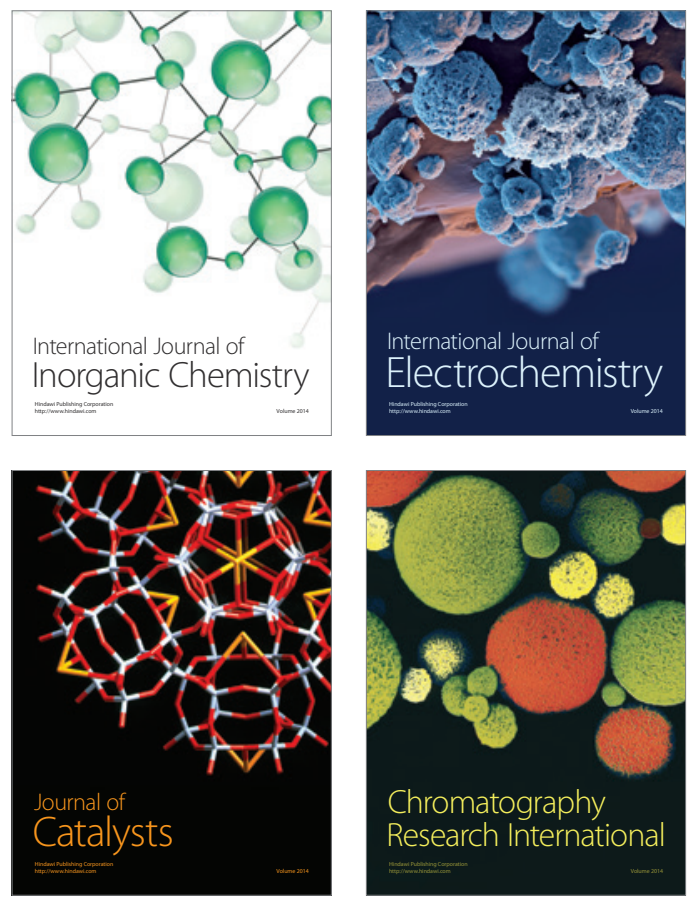
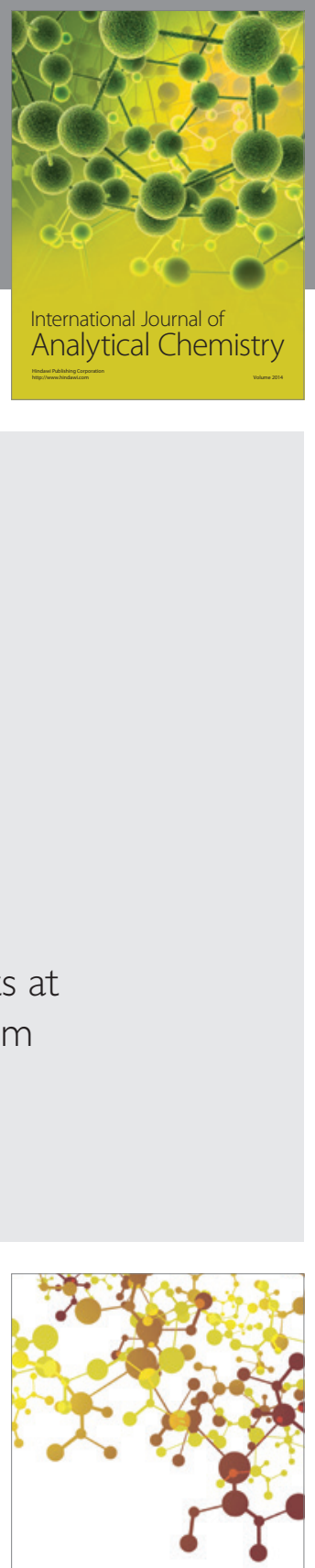

Journal of

Applied Chemistry
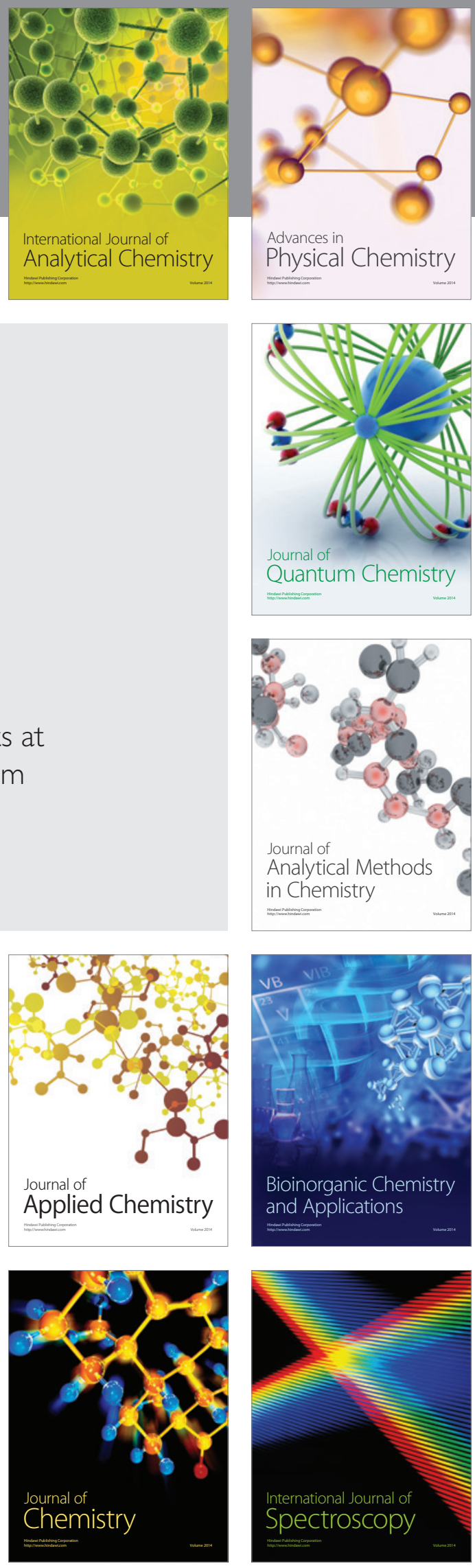